\title{
Potential factors contributing to the decline of Iris Yellow Spot Virus in organically grown onion crops in Canterbury and Hawke's Bay over three years
}

\author{
Melanie M. Davidson*, Mette-C. Nielsen, John D. Fletcher \\ The New Zealand Institute for Plant \& Food Research Limited, Private Bag 4704, Christchurch \\ Mail Centre, Christchurch 8140, New Zealand \\ ${ }^{*}$ Corresponding author: melanie.davidson@plantandfood.co.nz
}

\begin{abstract}
The Tospovirus Iris yellow spot virus (IYSV), transmitted by thrips (predominantly Thrips tabaci), was first recorded in New Zealand in 2007. In March 2015, symptoms of the virus were relatively widespread in an organically managed onion crop in Canterbury. Onion plants were sampled for the presence of T. tabaci adults and larvae and for IYSV symptoms on an organically managed farm in Canterbury in 2014-2015, 2015-16 and 2016-17, and on a similar farm in Hawke's Bay in 2014-2015 and 2015-16. An immunoassay was used to confirm the presence of IYSV in some symptomatic plants. In Canterbury, IYSV symptoms were less apparent in 2015-16 and no symptoms were observed in 2016-17. No IYSV symptoms were observed in the Hawke's Bay onion crop, despite relatively high T. tabaci numbers. The virus symptoms declined from when they were first observed in March 2015 to undetectable levels in 2016-17 in Canterbury, which may be attributed to crop location, fewer thrips and the absence of a disease reservoir in volunteer Allium cepa plants or other hosts.
\end{abstract}

Keywords Allium, onion thrips, Thrips tabaci, Tospovirus, Bunyaviridae, IYSV, viruliferous

\section{INTRODUCTION}

Onions (Allium cepa L.) are a widely used vegetable around the globe. Iris yellow spot virus (IYSV) (Tospovirus: Bunyaviridae) is found throughout most onion-growing regions of the world and is considered one of the most damaging viruses to attack onion crops (Gent et al. 2006; Bag et al. 2015). The virus is transmitted in a persistent, propagative manner by thrips vectors, similar to other tospoviruses (Gent et al. 2006), with onion thrips (Thrips tabaci) considered the main vector. However, recent research has shown the virus can be transmitted less efficiently by Frankliniella fusca, a thrips species not present in New Zealand (Srinivasan et al. 2012). Unlike other tospoviruses, IYSV has a relatively narrow host plant range (Gent et al. 2006; Smith et al. 2011). Infection by IYSV also tends to be localised, whereas other tosposviruses cause systemic infection (Smith et al. 2006).

Disease symptoms are characterised by diamond- or spindle-shaped lesions on the leaf composed of chlorotic or necrotic tissue with, or without, a distinctive green centre (Gent et al. 2004). The resultant decline in photosynthesis leads to reduced bulb size (Gent et al. 2004). The main method for managing IYSV is through reducing populations of thrips vectors, generally with the application of insecticides. However, growers of organically produced of onions in New Zealand are only allowed to use natural pyrethrums with restrictions (AsureQuality 2018).

IYSV was first reported in New Zealand in 2007 in samples of Allium species collected from the North and South Islands (Ward et al. 2009).

New Zealand Plant Protection 71: 39-44 (2018)

https://doi.org/10.30843/nzpp.2018.71.116 
IYSV has so far not developed as a serious disease in onion crops in New Zealand (unpublished data), aside from the organically managed onion crop reported in the present study. The aim of this study was to evaluate the vulnerability of organically managed onion crops to IYSV.

\section{MATERIALS AND METHODS}

A field study was conducted over three years. In 2014-15, onion crops were surveyed for $T$. tabaci and foliar pathogen-like symptoms as part of a larger study to determine biotic and abiotic variables that influence the quality of onion bulbs. Onion plants were surveyed in the field or collected for destructive sampling in two conventionally and one organically managed crop in Canterbury, an organically managed crop in Hawke's Bay, and two conventionally managed crops in Pukekohe. No insecticides were applied to the organically managed crops. Between 6 and 9 insecticides were applied to conventionally managed crops over the growing season including organophosphates, synthetic pyrethroids and neonicotinoids. The organic crops were relatively small ( $\leq 1 \mathrm{ha}$ ) and a mix or brown, red and spring onion varieties, while the conventionally managed crops were at least several hectares and predominantly brown onion varieties. Each onion crop was separated into four distinct blocks determined by the growth pattern of the onion plants or contours of the field (e.g. reduced plant vigour relative to other areas of the field, dry areas versus wet areas). Within each block, 20 adjacent plants were marked at the beginning of the study. The Hawke's Bay study site was sampled only in December 2014 but the other sites were sampled in December 2014 and again in January and February 2015. Following observations of IYSV-like symptoms in the organic crop in Canterbury in early March 2015, four leaf samples exhibiting the symptoms were collected from four plants at the Canterbury site on 20/03/2015 for immunoassay. Samples were placed individually into paper bags, transported to the laboratory and stored at room temperature until they could be tested. Also, at this time 100 plants in the field were randomly surveyed for
IYSV-like symptoms in the red onion varieties, which exhibited more symptoms that the adjacent brown onion crop. The red onion varieties had been established at a later date than the adjacent brown onion crop at this site.

In 2015-16, sampling for thrips and IYSVlike symptoms was carried out in an organic crop in Canterbury and one in Hawke's Bay. No organically managed onion crops were located in the Pukekohe region. The organic onion crop sampled in 2015-16 in Canterbury was located west, across a gravel road and within $40 \mathrm{~m}$ of the 2014-15 organic onion crop. The grower applied a single application of an approved pyrethrum in late December 2015. No insecticides were applied to the organic crop in Hawke's Bay. The onion crop in Canterbury was sampled monthly for thrips and IYSV-like symptoms from December 2015 to March 2016. The percentage of plants with IYSV-like symptoms was recorded within a $0.25 \mathrm{~m}^{2}$ quadrat for 15 randomly selected sites throughout the onion crop in February 2016 after symptoms had developed. The numbers of onion thrips adults and larvae were counted and presence of any IYSV-like symptoms recorded for 50 randomly selected plants in the field. Fewer plants were sampled in Hawke's Bay (40 randomly selected plants) due to the higher number of thrips found on the plants. In addition to thrips, plants in the Hawke's Bay onion crop were surveyed for the presence of IYSV-like lesions in December 2015 and January 2016. No IYSV-like symptoms were observed in Hawke's Bay, although a single plant with necrotic spots was collected from the crop in mid-January 2016 and couriered to Plant \& Food Research Lincoln for immunoassay testing. IYSV-like symptoms were observed in Canterbury. Consequently, 14 whole plants exhibiting IYSV-like symptoms were collected separately into paper bags on 11 February, 2016 and transported to the laboratory and stored at room temperature until they could be tested.

Chenopodium album L. was found in abundance around the organic onion crop in Canterbury and Hawke's Bay during this sampling period. Thrips adults and larvae were collected 
from one of the plants from the Canterbury site on 10 December, 2015 and two plants from the Hawke's Bay crop on 15 December, 2015.

In 2016-17, sampling for thrips and IYSV-like symptoms was only carried out in the organically managed crop in Canterbury, due to the absence of IYSV-like symptoms in the Hawke's Bay organically managed crop in 2015-16. The organic onion crop in Canterbury in 2016-17 was located approximately $500 \mathrm{~m}$ to the south of the 2015-16 crop, and $400 \mathrm{~m}$ south of the 2014-15 crop. No pyrethrum insecticides were applied to the crop. Thirty randomly selected onion plants were examined for onion thrips larvae and adults and the presence of IYSV-like symptoms in December 2016, January (early and late), February, and March 2017. Fewer plants were sampled compared to the previous year because data from the previous year suggested 30 plants would be adequate to evaluate thrips numbers. Five leaf samples with necrotic spots were collected from five plants into separate paper bags on 9 March 2017 and transported to the laboratory and stored at room temperature until they could be tested. The mean number of adult trips and the number of larvae from 2014$15,2015-16$ and 2016-17 were determined.

Immunoassay testing was used to confirm whether the symptoms observed could be attributed to IYSV, rather than an attempt to quantify virus in a crop, hence sample sizes were small. Leaf samples were collected from Canterbury organic onion crops in 2014-15 $(n=5), 2015-16 \quad(n=14)$ and 2016-17 $(n=5)$ and from Hawke's Bay a single onion plant was collected in mid-January 2016 exhibiting IYSVlike symptoms or necrotic spots. These plants were tested for the presence of IYSV using an enzyme linked immunosorbent assay (ELISA) to confirm the presence of the virus. In the laboratory, symptomatic lesions from fresh plant tissue (two replicates per plant) was weighed and extracted in PBS Tween ${ }^{\circledR}$ PVP buffer 1:10 wt/ vol. ELISA was conducted for IYSV according to the manufacturer's instructions (Agdia, Elkhart, USA).

\section{RESULTS}

The number of thrips adults and the number of larvae from 2014-15, 2015-16 and 2016-17 at one organically managed crop in Canterbury and one organically managed crop in Hawke's Bay are displayed graphically in Figure 1 along with mean values for each region. Very few onion thrips were found in the conventionally managed crops in Canterbury and Pukekohe (data not shown). In March 2015, IYSV-like symptoms were widespread intermittently throughout brown onion varieties in an organically managed crop in Canterbury. The irregular spread of the IYSV-like symptoms made it difficult to estimate

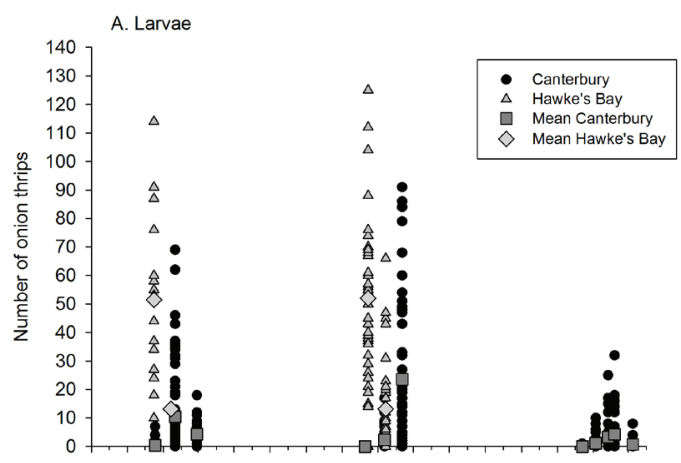

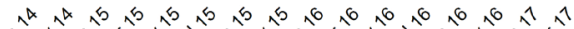

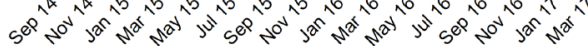

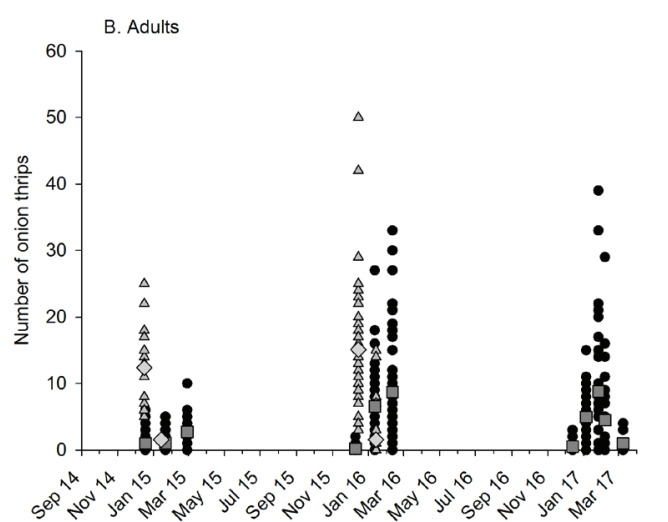

Figure 1 The number and mean of thrips (A) larvae or (B) adults recorded on plants sampled in the field of an organically managed onion crop in Canterbury and one in Hawke's Bay annually over 3 years. Note different $y$-axis scales. 
overall putative infection in the field. However, in the areas of the onion crop with highest incidence of IYSV-like symptoms, 90\% (18 plants) had typical IYSV leaf lesions, 75\% (15 plants) were stunted and overall, bulbs appeared smaller than expected. One out of the four leaf samples collected from the organically managed brown onion crop in Canterbury on 20 March 2015 tested with ELISA was positive for IYSV. Among the red onion varieties at this site, 9 out of 100 plants randomly surveyed had IYSV-like lesions. Analysis of a single leaf exhibiting the symptoms obtained from the red onion crop on 20 March 2015 confirmed the presence of IYSV in that individual sample. Numbers of onion thrips were very low in the conventionally managed crops in Canterbury and Pukekohe and no IYSV-like symptoms were observed on any of the plants sampled in these crops (data not shown). No IYSV-like symptoms were observed in the organically managed onion crop in Hawke's Bay despite relatively high numbers of onion thrips (Fig. 1).

Between 5 and $45 \%$ of the onion plants within 12 of the 15 quadrats sampled in February 2016 throughout the field in Canterbury had at least one IYSV-like lesion present on a leaf. IYSV-like lesions tended to be small $(<5 \mathrm{~mm})$. Using the ELISA assay, IYSV was confirmed present in 71\% of the 14 leaf samples with IYSV-like symptoms collected from the Canterbury organic onion crop in February 2016. Numbers of thrips larvae and adults were similar to 2014-15 (Fig. 1). Despite thrips numbers being higher in Hawke's Bay than Canterbury, no IYSV-like symptoms were observed in the Hawke's Bay organic crop. A single leaf sample with necrotic lesions from the 2015-2016 Hawke's Bay crop tested negative for the presence of IYSV from ELISA analysis.

Numbers of onion thrips larvae were somewhat lower in 2016-17 than the previous year, although numbers of adults were similar between the years (Fig. 1). No pyrethrum insecticides were applied to the crop. No IYSVlike symptoms were observed and none of the five leaf samples with necrotic spots collected tested positive for IYSV from the ELISA analysis.

\section{DISCUSSION}

Despite the presence and relative abundance of onion thrips capable of vectoring IYSV, the incidence of virus symptoms in organically managed onion crops in Canterbury declined over the 3 years of this study. No virus symptoms were ever observed in the Hawke's Bay organic crops, despite having higher numbers of onion thrips than in Canterbury. The decline in Canterbury crops may be due to a combination of factors, including low numbers of viruliferous thrips, the absence of a disease reservoir in volunteer Allium or other host plant species, and the spatial variability in crop location between years. For thrips to become viruliferous, the first and early second instars must acquire the virus through feeding on infected hosts (Moritz et al. 2004). IYSV is not transovarially transmitted from adult females to progeny, as with other tospoviruses. Once a thrips larva has acquired the virus it remains virulent for the rest of its life. In colder regions such as upstate New York, USA, where onion thrips overwinter as adults (Larentzaki et al. 2007), any surviving overwintering adults that had acquired IYSV in autumn will therefore be able to transmit the virus in spring. It is not known whether or not onion thrips in Canterbury remain as adults over the winter months (i.e. experience cold quiescence or enter a diapause phase). Martin (2015) reported that there was no diapause in onion thrips populations in the South Auckland region. Populations that lack a diapause could, therefore, lose IYSV if the thrips adults continue to live and their progeny develop on plant species that are not hosts of the virus.

The host plant range for IYSV is more limited than that of onion thrips, with only 47 species listed world-wide (Gent et al. 2006; Smith et al. 2011). Of these, 15 species are found as common weeds or crop plants in New Zealand (Popay et al. 2010). Such hosts may provide a temporal green bridge between onion crops, enabling onion thrips to acquire IYSV from infected perennial hosts or volunteer crop plants that then migrate to emerging onion crops (Gent et al 2004). One IYSV host weed species, Chenopodium album 
was found in abundance around the organic onion crop in Canterbury during the 2015-16 sampling period, from which onion thrips adults and larvae were collected. However, no C. album plants were tested for the virus, so it not known if they were infected with IYSV. Given that IYSV was recorded in the same crop in 2015-16 there were likely to have been plants of one or more IYSV host species present nearby between the first two sampling years that provided a temporal bridge between onion crops. However, C. album is an annual plant that is killed by frost (which occurred between the two crop seasons) (Popay et al. 2010), so it is unlikely that this species was the one that provided such a bridge between onion crops. Alternatively, thrips adults that acquired the virus in the autumn of 2015 and entered diapause over winter would have remained viruliferous over winter, and could have dispersed to the onion crop the following spring.

For thrips to vector the virus to the onion crop in 2016-17, adult viruliferous thrips would have had to travel $400-500 \mathrm{~m}$ from the vicinity of the previous onion crops in autumn or spring 2016. Any such thrips adults would either have to colonise an IYSV host plant species or enter diapause. If development of the virulent thrips continued through winter, the young larvae would then need to acquire the virus from the host plant. Even if such host plants were available, IYSV infections tend to remain localised (Smith et al. 2006) and this may limit the frequency that thrips larvae encounter the virus in a host plant, consequently constraining the number of virulent thrips vectors within a given population.

It is probable that thrips would be capable of dispersing 400-500 m given onion thrips are regularly caught in $7.5-\mathrm{m}$ tall suction traps around New Zealand (Nielsen et al. 2004) and have been caught on sticky traps attached to unmanned aerial vehicles 50-60 m above onion crops in New York State, USA (Smith et al. 2015). Therefore, it is possible that onion thrips that developed in the vicinity of the onion crops sampled in the first two years could have moved to the onion crop in the final year of sampling.
However, the proportion of onion thrips that would travel $400-500 \mathrm{~m}$ between crop sites, and, of those, the proportion that could be carrying IYSV may have been relatively low. Smith et al. (2015) reported 96\% of thrips were caught on sticky traps that were $<2 \mathrm{~m}$ above ground compared with traps at 4 and $6 \mathrm{~m}$ above ground. This suggests that in an onion crop, the majority of thrips were engaged in short-distance, trivial flights (movement within a habitat) (Smith et al. 2015).

The present study found that, despite the presence of potential thrips vectors, the incidence of IYSV declined. The method used in the present study to determine virus incidence was based on visual assessments, with some validation through immunoassay testing. The ELISA technique is generally less sensitive than molecular methods, such as reverse transcriptase polymerase chain reaction (Jeong \& Noh 2014). However, the ELISA test used in the present study did confirm that IYSV was present in some plant material. In order to elucidate the epidemiology of IYSV in and around onion crops future research to; determine the overwintering dynamics of onion thrips in Canterbury, the incidence of IYSV in populations of onion thrips, the movement of onion thrips between host plants, the impact of abiotic factors on onion thrips abundance, and the abundance and distribution of weeds and incidence of IYSV in these weed populations is warranted.

\section{ACKNOWLEDGEMENTS}

We wish to thank the growers and especially Tim Chamberlain for access to their onion crops. We also thank Aliesha Kean for her technical assistance. The project was funded by The New Zealand Institute for Plant and Food Research Limited Strategic Science Investment Fund. 


\section{REFERENCES}

AsureQuality 2018. AsureQuality Organic Standard. AsureQuality. Pp. 120. https:// www.asurequality.com/assets/Organic-Files/ organics-standard-2015-FULL-V6-Feb16. pdf

Bag S, Schwartz HF, Cramer CS, Havey MJ, Pappu HR 2015. Iris yellow spot virus (Tospovirus: Bunyaviridae): from obscurity to research priority. Molecular Plant Pathology 16: 224237.

Gent DH, Schwartz HF, Khosla R 2004. Distribution and incidence of Iris yellow spot virus in Colorado and its relation to onion plant population and yield. Plant Disease 88: 446-452.

Gent DH, du Toit LJ, Fichtner SF, Mohan SK, Pappu HR, Schwartz HF 2006. Iris yellow spot virus: An emerging threat to onion bulb and seed production. Plant Disease 90: 14681480.

Jeong Jj, Noh HjJ 2014. A review of detection methods for the plant viruses. Research in Plant Disease 20: 173-181.

Larentzaki E, Shelton AM, Musser FR, Nault BA, Plate J 2007. Overwintering locations and hosts for onion thrips (Thysanoptera: Thripidae) in the onion cropping ecosystem in New York. Journal of Economic Entomology 100: 1194-1200.

Martin NA 2015. Onion thrips, Thrips tabaci (Thysanoptera: Thripidae), overwintering in South Auckland, New Zealand: the importance of the local bionomic data/ temperature model and biosecurity implications. New Zealand Entomologist 38: 17-27.

Moritz G, Kumm S, Mound LA 2004. Tospovirus transmission depends on thrips ontogeny. Virus Research 100: 143-149.

Nielsen MC, Fletcher CD, Teulon DAJ 2004. Monitoring thrips flight with 7.5 metre high suction traps (Poster abstract). New Zealand Plant Protection 57: 339.

Popay I, Champion P, James T 2010. An Illustrated Guide to Common Weeds of New Zealand. 3rd ed. Christchurch, New Zealand,
New Zealand Plant Protection Society (Inc.). Smith TN, Wylie SJ, Coutts BA, Jones RAC 2006. Localized distribution of Iris yellow spot virus within leeks and its reliable large-scale detection. Plant Disease 90: 729-733.

Smith EA, Ditommaso A, Fuchs M, Shelton AM, Nault BA 2011. Weed hosts for onion thrips (Thysanoptera: Thripidae) and their potential role in the epidemiology of Iris yellow spot virus in an onion ecosystem. Environmental Entomology 40: 194-203.

Smith EA, Fuchs M, Shields EJ, Nault BA 2015. Long-distance dispersal potential for onion thrips (Thysanoptera: Thripidae) and Iris yellow spot virus (Bunyaviridae: Tospovirus) in an onion ecosystem. Environmental Entomology 44: 921-930.

Srinivasan R, Sundaraj S, Pappu HR, Diffie S, Riley DG, Gitaitis RD 2012. Transmission of Iris yellow spot virus by Frankliniella fusca and Thrips tabaci (Thysanoptera: Thripidae). Journal of Economic Entomology 105: 40-47. Ward LI, Perez-Egusquiza Z, Fletcher JD, Ochoa Corona FM, Tang JZ, Liefting LW, Martin EJ, Quinn BD, Pappu HR, Clover GRG 2009. First report of Iris yellow spot virus on Allium cepa in New Zealand. Plant Pathology 58: 406-406. 